\title{
FACTORS IMPROVING BUS TRANSFERABILITY AS THE CHOICE-MODE OF PASSENGERS AT BAMBALAPITIYA RAILWAY STATION
}

\author{
C T Danthanarayana ${ }^{a *}$ and W GH A Welarathna ${ }^{b}$ \\ a b Department of Economics, University of Colombo, Sri Lanka \\ * Corresponding author E-mail address: chamila@econ.cmb.ac.lk
}

\begin{abstract}
Inadequacy and inefficiency of public bus transport as a mode of transfer at railway stations has led passengers to switch other modes to reach their destinations. This has led to increased traffic congestion on urban roads and heavy economic cost to society.

The main objective of this study is to identify the factors influencing the improvement of bus transferability at the Bambalapitiya Railway station. This study considered sixteen attributes of quality: accessibility, waiting time, cleanliness of the bus stop, facilities of the bus stop, occupancy level, safety of driving, traffic conflict, harassments, courtesy of bus crew, bus route coverage, bus frequency, availability, bus quality, privacy, cleanliness and travel time.

The findings of the descriptive analysis clearly showed overcrowding and increased travel time as crucial factors for not using the existing transfer bus service. As per the results of factor analysis, the six factors which contain the sixteen attributes are network design, convenience, and safety, quality of buses, background factors, and time consumption.

Prioritising the deployment of additional buses during peak hours, introduction of new bus services with integrated scheduling, the assurance of quality, and efficient service are imperative to enhancing bus transferability at the railway station.
\end{abstract}

Keywords: Transferability, Quality Attributes, Bus Transit, Factor Analysis, ModeChoice 


\section{INTRODUCTION}

Public bus transport is one of the integral transfer modes in an integrated transport system that facilitates an efficient and effective service by increasing economic and social benefits. Public transport probably the most up-to-date answer to the growing need for relieving traffic congestion, associated environmental problems, and continuously increasing cost of transferring passengers [1]. Bus transit provides accessibility to fulfil the daily requirements of people facilitating regional connectivity. A transport journey links different modes as per the choice of passengers. According to Castiglione [2], people consider the choice of travel modes according to their trip purpose that required to be fulfilled. This reveals that mode choice varies according to expectations and satisfaction of passengers on the level of service provision.

In Sri Lanka, the majority of people use public bus transport for their daily movements and this is shown by the mode share of bus transport which accounts for $46.6 \%$ including private and SLTB buses [3]. However, the non-availability of proper transport connectivity between different modes has created a long journey time with many discomforts to the passengers. Bus transport is a cost-effective transfer mode that could make proper connectivity between road and rail. The lack of a rail-bus integrating system in Sri Lanka has caused people to choose private vehicles as their transfer mode to reach their destinations. This has led to increased traffic congestion mainly on urban roads whereas creating a heavy economic cost to society. In the Sri Lankan context, many people use rail transport to fulfil their work trips and trains are more crowded during peak periods due to congestion on roads. People attract rail transport as it provides affordable service with shortened travel time compared to buses and other private transport services. Thus, facilitating bus transferability at railway stations to capture transfer passengers is timely imperative as it minimises externalities on roads whereas making passenger access to destinations easier and more affordable.

At present there is no coordinated effort for intermodal transportation and hence there is a breakdown of inter-modalism between trains and buses [4]. Since rail-bus integration and development of public transport services are key aspects of transport policy priorities in Sri Lanka, the study provides guidance to the transport policymakers and planners to improve passenger accessibility by improving transfer bus services. In the global context, many kinds of research have ascertained the factors of mode choice and passenger satisfaction to develop the public transport system. But, in the Sri Lankan context, research conducted to identify the determinants of transfer mode choice for improving bus transferability or rail-bus integration is deficient. Hence, determining the factors of transfer mode choice is imperative to upgrade the prevailing transfer bus services at railway stations as well as introducing new transfer services. 
The main objective of this study is to identify the influential factors of improving bus transferability as the choice mode of passengers at the Bambalapitiya Railway Station. Accordingly, the main motivation of this study is to determine which service attributes in public bus service (private/government) make people use them as their transfer mode and identify the user requirements for satisfaction of prevailing transfer bus service. The study focuses on the group of passengers who are currently not using the transfer bus service commencing at the Bambalapitiya Railway Station to ascertain the causality for their non-usage. The study first assesses the causalities of passengers for not choosing bus transit. Second, the study examines the important quality aspects that influence passenger transferability. Finally, the study evaluates the quality attributes identified and ascertains the most influential factors to determine the quality improvement priorities to upgrade the prevailing bus service at the Bambalapitiya Railway Station.

\section{LITERATURE REVIEW}

A transfer allows the rider of a public transportation vehicle who pays for a single-trip fare to continue the trip on another bus or train [5]. Facilitating transfer service is a key element of an integrated transport system. Previous studies on bus transferability focused on the planning of a proper timetabling system to minimise passenger transfer time while improving the efficiency of rail-bus integration. The determinants of improving transfer bus services depend upon passenger mode choice and passenger satisfaction. According to Mintesnot and Shin [6], travellers' satisfaction is an important performance measure for the transport service providers and a determinant factor affecting the mode choice. The factors of transport mode choice can be classified as characteristics of the trip maker, characteristics of the trip, characteristics of mode as well as many latent factors like comfort and convenience [7]. Cheng et al. [8] analysed factors that affect passenger satisfaction during the bus transfer process at HSR stations based on the passengers' perceptions of convenience, comfort, safety, service, and economy. The results of analysis show that economy and convenience are the critical influential indicators of passenger satisfaction, among which bus fare preferential policy and transfer distance are the most significant factors.

Researchers is generally focused on improving the quality of bus service that connects with the perceived value, and satisfaction of public transport. Nielsen et al [9] mentioned that public transport quality denotes regularity, direct connections, convenient terminal layout, high and fixed frequencies, and short travel times. They further noted these quality aspects are important for the choice of public transport vs private transport. The factors influencing bus transferability can be ascertained through the viewpoint of users on mode choice, exploring the reasons and their level of satisfaction on service quality. Berkley [10] mentioned that customers could supply 
excellent sources of information and, according to the feedback from customers, governments and companies could improve service quality by distinguishing the areas of services most needed improvement. According to Leonard et al. [11], the only judge of the service quality is the customer. This reveals that identifying customer perspectives on mode choice and satisfaction is very useful for decision making on public transport planning and operation. A person's behavioural intention may also affect transport mode choice [12]-[15].

Customer satisfaction, closely related to perceived service quality and value [16-18], is widely regarded as the main driver of consumer loyalty to public transport and behaviour [19]. Improving service quality could lead to higher passenger satisfaction, which could increase the ridership of public transport [8]. He further mentioned that from the view of service supply, the choice of transfer mode for a passenger at a highspeed railway station is influenced by the service quality of both the transfer process and the target traffic mode. Nor et al [20] forecasted that improvements in bus service quality increase ridership depending on trip purpose.

Factors such as connectivity or reach, accessibility to a specific mode of transportation, information, time satisfaction, user attendance, comfort, security and safety, and environmental impact have been identified to be influential in the choice of a commuter [21]. According to Popuri et al [22], reliability, privacy, comfort, availability, safety, and attitudes towards public transportation were key factors in transportation preference of commuters in the Chicago area in the United States. This reveals passenger preference on transit modes is influenced by service quality and operational performance.

According to the existing studies, from the passengers' perspective, comfort, facilities, reliability, waiting time, journey time, convenience, travel cost, punctuality, and accessibility have been considered as the main factors that affect the quality of service. Shaaban and Khalil [23] stated that individual socioeconomic attributes could affect passenger satisfaction, such as gender, age, occupation, income, and marital status. This shows the personal attributes of passengers are crucial factors affecting travel mode choice behavior. Abdel-Aty and Jovanis [24] found that departure time had a significant impact on the travel behaviour of the elderly. Redman et al [25] pointed out that numerous attributes have been proposed to define public travel quality, which can roughly be classified as physical (reliability, frequency, speed, accessibility, price, etc.) or perception (comfort, safety, convenience, aesthetics, etc.). According to [26] passengers always tend to choose the travel modes meeting their expectations of the service performance to the maximum extent.

Kostakis [27] researched on measuring customer satisfaction in urban buses in Greece and found that route waiting time and frequency are the major determinants directly influencing customer satisfaction. Munzilah et al [28] stated that the choice of public 
transport as a preferred mode of travel is mainly influenced by the quality of bus operation services. They further mentioned transit users today are more demanding from the bus providers including fast and reliable service, shorter walking distance to stops, low floor buses, cheaper service, and friendly safe drivers. The performance of the bus transferability at stations depends on service quality and efficiency expected by passengers. Madhuwanthi et al [29] conducted research on factors influencing travel behaviour on transport mode choice and identified that vehicle ownership, safety and comfort become the most crucial factors.

Research studies of Mazzulla and Eboli [30] analysed public transport non-use reasons why passengers did not use public transport. According to the analysis, the main reasons for not using public transport are low service frequency followed by vehicle overcrowding, slowness of the vehicles, and long waits at the stop. The Land Transport Authority of Singapore [31] conducted a survey on transport customer satisfaction to determine passenger expectations and identified service attributes for improvement. The survey determined the three most important service attributes: waiting time, travel time, and reliability which provide guidance to enhance the public transport service level for commuter benefit. According to Taylor and Fink [32] service reliability, particularly service coverage and service frequency are the most crucial factors influencing public transport ridership.

The literature review clearly shows that people tend to choose transfer mode with concerning the comfort, security, vehicle in time, trip distance, time reliability, cost of the travel mode, availability, and frequency of services, etc. since people have various opportunities to choose the mode in the present context. Mode choice analysis is vital to organise transportation and adjust operation plan effectively [33]. Hence, determining the factors of transport passenger mode choice and passenger satisfaction, travellers' behaviour and ridership patterns are important aspects of improving transfer bus services.

\section{METHODOLOGY}

Bambalapitiya Railway Station is located on the Coastline between Kollupitiya and Wellawatte Railway Stations in the Colombo district of Sri Lanka. It is the fourth Railway station located $5.22 \mathrm{~km}$ away from Colombo Fort. Bambalapitiya Station is a major transfer point to many suburban areas and main cities in the Colombo District. The station is accessed by many commuters with a high loading level during morning and evening peaks. At present, three bus services: Bambalapitiya-Dematagoda (154), Bambalapitiya-Kadawatha (177), and Bambalapitiya- Sethsiripaya (154) are operated from Bambalapitiya railway station. The services operate during morning peak hours (From $6.00 \mathrm{am}$ to $10.00 \mathrm{am}$ ) to target the working population arriving at Bambalapitiya Railway Station. 
Since heavy road traffic congestion occurs during this time period and passengers are facing inconveniences to reach their destinations, improving the transferability of prevailing bus services and introducing new transfer bus services are a paramount solution to enhance passenger mobility and accessibility. The passengers who transfer from the Bambalapitiya Railway Station mainly use state and private buses, para transits, or office transport services as their egress modes. The study is based on the quantitative research method and collected primary data from passengers who are currently not using public bus transport as their transfer mode at the Bambalapitiya Station. Further, the study focused on passengers who make mode choice as their egress mode. A structured questionnaire with five-point Likert scale was used to ascertain passenger experience and opinions of different mode choices. The study was conducted during the morning peak which could be identified many transfers. Among the total population of the survey which consists of total transfer passengers from the Bambalapitiya station from $6.00 \mathrm{am}$ to $10.00 \mathrm{am}, 150$ passengers were randomly selected as the sample. The survey is based on the identified factors of service quality attributes and the factors were tested on passengers' perspectives. Sixteen key quality attributes (accessibility, waiting time, cleanliness of the bus stop, facilities of the bus stop, occupancy level, safety of driving, traffic conflict, harassments, curtsey of bus crew, bus route coverage, bus frequency, availability, bus quality, privacy, cleanliness and travel time) that influence passengers' transfer mode choice were used in this study and the selection of the quality attributes was based on the literature survey and brainstorming.

Data analysis is based on the evaluation of passengers' level of agreeability on service quality. A five-point Likert scale with "Highly Agree (HA)" equalling 5, "Agree (A)" equalling 4, "Neutral (N)" equalling 3, "Disagree (D)" equalling 2, and "Highly Disagree (HD)" equalling 1, was used in the rating of the questions for the assessment of passengers' mode choice. A descriptive analysis and factor analysis were used to examine the underlying constructs. First, correlation analysis was undertaken to measure the linear correlation between quality attributes, and factor analysis was performed to cluster them using SPSS software.

\section{RESULTS AND DISCUSSION}

\subsection{Analysis of Descriptive Statistics}

According to the analysis of socio-economic data, the sample consisted of $57 \%$ female and $43 \%$ male passengers in different age groups. The highest age group categories who are not using bus transport as their transfer mode are 20-30 years (32\%) and 30-40 years (23\%) which represent almost half of the total sample. As per the analysis of employment status, the majority of people who are not using bus transfer service are employed as office workers and businesspeople (51\%). As per the 
frequency of usage, $55 \%$ of passengers used transfer services 'mostly' and $18 \%$ of passengers used 'on average' to reach their destination. This shows the majority of rail transport users regularly choose different services as their egress mode. Further, the majority of the sample has a wide experience of existing transfer modes and their quality as regular passengers.

Table 1 depicts descriptive statistics for quality attributes under investigation. The descriptive analysis shows passengers agreed that considerations related to accessibility, waiting time, occupancy level, harassments, courtesy of bus crew, bus frequency, privacy, and travel time (Mean >3.0) for not using bus transfer service. The quality attributes passengers are most concerned with are high occupancy level $(\mathrm{Mean}=4.3)$ and travel time taken to complete their journey $(\mathrm{Mean}=4.6)$ that reflects the most crucial factors on transfer mode choice.

Table 1: Descriptive Statistics

\begin{tabular}{|l|c|c|c|c|c|}
\hline \multicolumn{1}{|c|}{$\begin{array}{c}\text { Component (Quality } \\
\text { Attribute) }\end{array}$} & $\mathrm{N}$ & Minimum & Maximum & Mean & Std. Deviation \\
\hline Accessibility & 150 & 1.0 & 5.0 & 3.213 & 1.5910 \\
Waiting Time & 150 & 1.0 & 5.0 & 3.033 & 1.3581 \\
Cleanliness of Bus stop & 150 & 1.0 & 5.0 & 2.053 & .6833 \\
Facilities of Bus stop & 150 & 1.0 & 5.0 & 2.567 & 1.1138 \\
Occupancy Level & 150 & 1.0 & 5.0 & 4.353 & .9772 \\
Safety of Driving & 150 & 1.0 & 5.0 & 2.767 & 1.0832 \\
Traffic Conflict & 150 & 1.0 & 5.0 & 2.033 & .9005 \\
Harassments & 150 & 1.0 & 5.0 & 3.033 & 1.4536 \\
Curtsey of Bus Crew & 150 & 1.0 & 5.0 & 3.533 & .9530 \\
Bus Route Coverage & 150 & 1.0 & 5.0 & 2.933 & 1.2674 \\
Bus Frequency & 150 & 1.0 & 5.0 & 3.167 & 1.3532 \\
Availability & 150 & 1.0 & 5.0 & 2.820 & 1.7573 \\
Bus Quality & 150 & 1.0 & 5.0 & 2.527 & .9603 \\
Privacy & 150 & 1.0 & 5.0 & 3.900 & .9814 \\
Cleanliness & 150 & 1.0 & 5.0 & 2.300 & .8956 \\
Travel Time & 150 & 2.0 & 5.0 & 4.593 & .6564 \\
Valid N (listwise) & 150 & & & & \\
\hline
\end{tabular}

Source: Author 


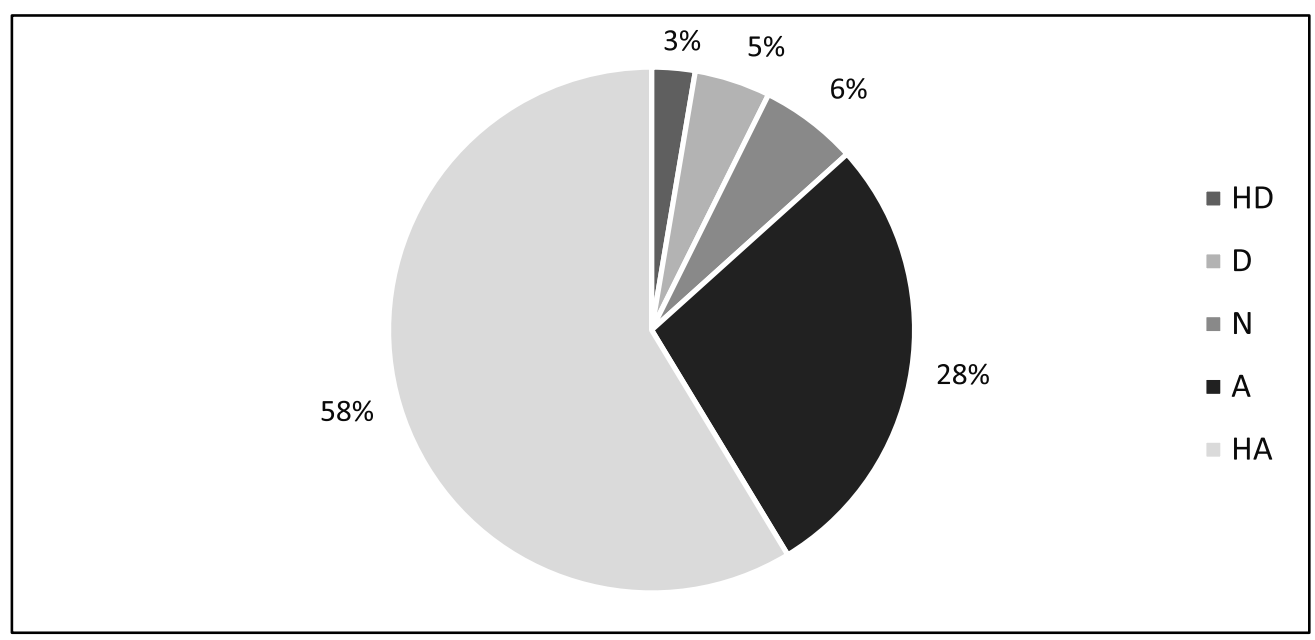

Figure 1: Passengers Perspective about Occupancy Level of Transfer Bus Service

Statistics shows that $86 \%$ of passengers considered the high passenger occupancy level (Figure 1), and 95\% passengers considered the high travel time associated with the prevailing transfer bus service as the reasons for not using buses as their egress mode (Figure 2).

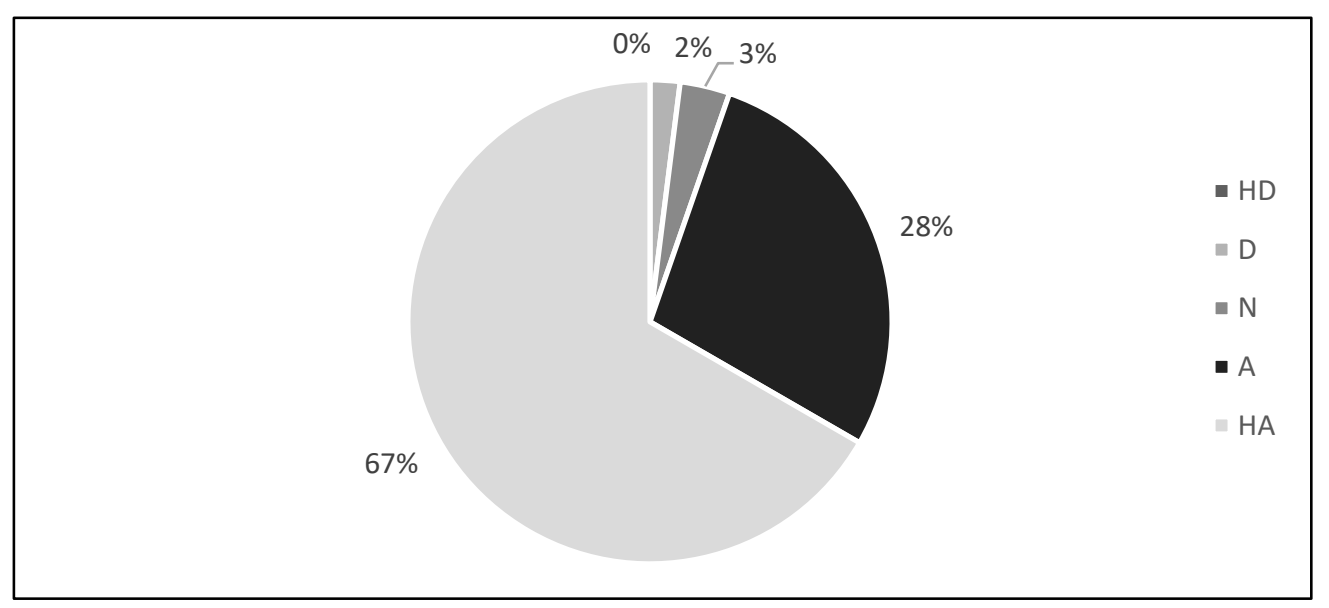

Figure 2: Passenger Perspective about Travel Time of Transfer Bus Service

\subsection{Factor Analysis}

The factor analysis produces a small number of factors from a large number of variables which is capable of explaining the observed variance in the larger number of variables. The Exploratory Factor Analysis (EFA) was carried out in the study for the selected 16 quality attributes that contribute to the transfer mode choice at Bambalapitiya Station. 
The test for the validity of the dataset was examined according to Kaiser- MeyerOhlin (KMO) measure of sample adequacy and Barlett's test of sphericity (Table 2). According to Kaiser-Meyer-Olkin (KMO) measure of sampling adequacy, the study shows KMO value of 0.613 , confirming acceptance of the model for factor analysis to proceed. KMO value more than 0.5 score implies the analysis could be continued further for all given factors in the study. The Bartlett's significant score (Sig. $=0.000$ ) indicates that the variables are relevant and suitable for structure detection. The test result shows the strength of the relationship among variables indicating that the correlation matrix is not an identity matrix.

Table 2: Results of Kaiser-Meyer-Ohlin [KMO] Measure and Bartlett's Test

\begin{tabular}{|c|c|c|}
\hline \multicolumn{2}{|c|}{ Kaiser-Meyer-Olkin Measure of Sampling Adequacy. } & .613 \\
\hline Bartlett's Test of Sphericity & $\begin{array}{l}\text { Approx. Chi-Square } \\
\text { df } \\
\text { Sig. }\end{array}$ & $\begin{array}{c}508.518 \\
120 \\
.000\end{array}$ \\
\hline
\end{tabular}

Source: Author

Table 3: Total Variance Explained

\begin{tabular}{|c|c|c|c|c|c|c|c|c|c|}
\hline \multirow{2}{*}{$\begin{array}{r} \\
\\
\\
\end{array}$} & \multicolumn{3}{|c|}{ Initial Eigenvalues } & \multicolumn{3}{|c|}{$\begin{array}{l}\text { Extraction Sums of } \\
\text { Squared Loadings }\end{array}$} & \multicolumn{3}{|c|}{$\begin{array}{c}\text { Rotation Sums of Squared } \\
\text { Loadings }\end{array}$} \\
\hline & 苞 & 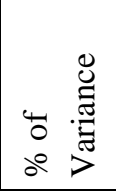 & 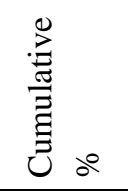 & 丞 & 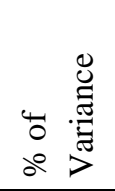 & 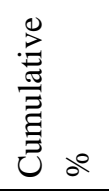 & : & 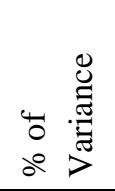 & 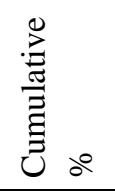 \\
\hline 1 & 2.673 & 16.708 & 16.708 & 2.673 & 16.708 & 16.708 & 2.159 & 13.494 & 13.494 \\
\hline 2 & 2.476 & 15.477 & 32.185 & 2.476 & 15.477 & 32.185 & 2.123 & 13.267 & 26.762 \\
\hline 3 & 1.836 & 11.476 & 43.661 & 1.836 & 11.476 & 43.661 & 1.789 & 11.181 & 37.942 \\
\hline 4 & 1.250 & 7.812 & 51.473 & 1.250 & 7.812 & 51.473 & 1.735 & 10.844 & 48.786 \\
\hline 5 & 1.149 & 7.181 & 58.654 & 1.149 & 7.181 & 58.654 & 1.399 & 8.744 & 57.531 \\
\hline 6 & 1.028 & 6.428 & 65.082 & 1.028 & 6.428 & 65.082 & 1.208 & 7.551 & 65.082 \\
\hline 7 & .862 & 5.390 & 70.472 & & & & & & \\
\hline 8 & .770 & 4.814 & 75.286 & & & & & & \\
\hline 9 & .727 & 4.544 & 79.829 & & & & & & \\
\hline 10 & .615 & 3.842 & 83.671 & & & & & & \\
\hline 11 & .568 & 3.548 & 87.219 & & & & & & \\
\hline 12 & .541 & 3.382 & 90.601 & & & & & & \\
\hline 13 & .493 & 3.080 & 93.681 & & & & & & \\
\hline 14 & .446 & 2.787 & 96.468 & & & & & & \\
\hline 15 & .311 & 1.942 & 98.410 & & & & & & \\
\hline 16 & .254 & 1.590 & 100.000 & & & & & & \\
\hline
\end{tabular}

Source: Author

Extraction Method: Principal Component Analysis. 
Table 3 above shows all the factors extractable from the analysis along with their eigenvalues that met with the cut-off criterion (extraction method). As per the percentage of variance attributable to each factor after extraction (Extraction Sums of Squared Loadings $\%$ of variance), six factors were identified which would contribute to improving bus transfer service.

Figure 3 shows the scree plot of eigenvalues against all the factors. The graph clearly shows that the curve begins to flatten after the factors 6 and it is noticeable that factor 7 onwards have an eigenvalue of less than 1, so only six factors have been retained as per the analysis.

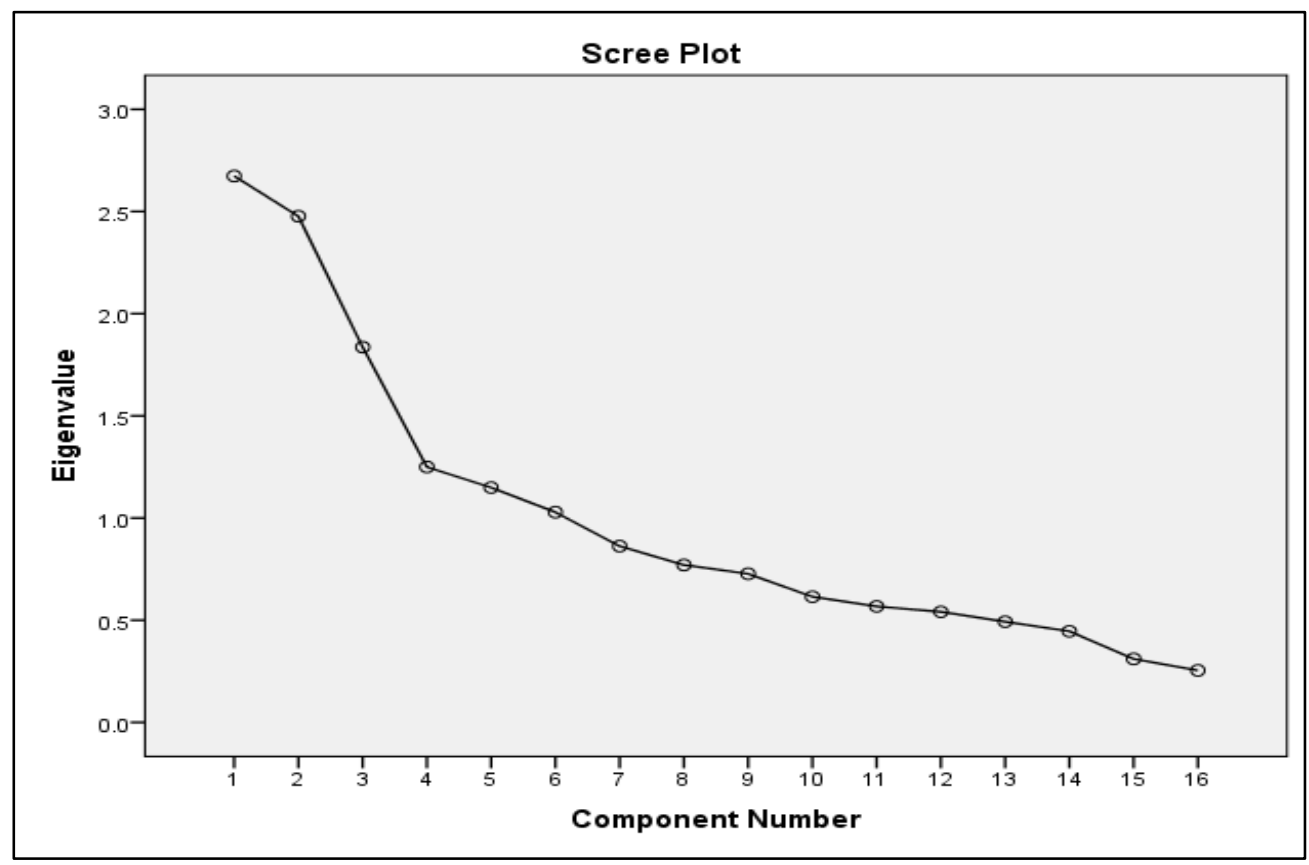

Figure 3: Factor Scree Plot

The idea of factor rotation is to reduce the number of factors on which the variables under investigation have high loadings. As per Table 4, three variables named bus route coverage, bus frequency, and availability are loaded on factor one named 'Network Design.' The next three variables named privacy, curtsey of bus crew, and occupancy level are in the second factor named 'Convenience'. The third factor named 'Safety' contains variables of harassments, safety of driving, and Traffic Conflict. The fourth factor named 'Quality of Buses' contains two variables of bus quality and cleanliness. The fifth factor named 'Background Factors' contains variables facilities of the bus stop, cleanliness of bus stop, and accessibility. The sixth factor named 'Time Consumption' contains variable waiting time and travel time of buses. 
Table 4: Rotated Component Matrix

\begin{tabular}{|c|c|c|c|c|c|c|}
\hline \multirow[b]{2}{*}{$\begin{array}{l}\text { Component } \\
\text { (Quality Attribute) }\end{array}$} & \multicolumn{6}{|c|}{ Factor } \\
\hline & 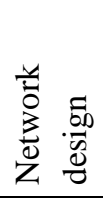 & 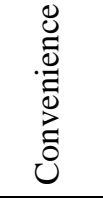 & 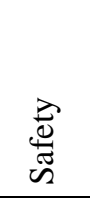 & 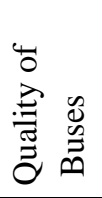 & 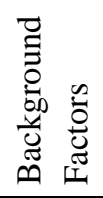 & : \\
\hline Bus Route Coverage & .869 & .016 & .006 & .096 & .002 & -.137 \\
\hline Bus Frequency & .843 & .021 & -.058 & -.031 & .107 & .155 \\
\hline Availability & .632 & -.267 & .133 & -.146 & .163 & .242 \\
\hline Privacy & -.029 & .769 & .017 & .173 & -.064 & -.081 \\
\hline Curtsey of Bus Crew & -.105 & .659 & .335 & .110 & .110 & -.048 \\
\hline Occupancy Level & -.011 & .627 & .245 & -.243 & .005 & .246 \\
\hline Harassments & -.153 & .136 & .769 & -.039 & -.056 & .046 \\
\hline Safety of Driving & .084 & .305 & .663 & .131 & .128 & -.067 \\
\hline Traffic Conflict & .196 & -.098 & .658 & .347 & -.026 & .035 \\
\hline Bus Quality & .023 & .040 & .178 & .847 & -.050 & -.035 \\
\hline Cleanliness of Buses & -.056 & .035 & .068 & .803 & .142 & .137 \\
\hline Facilities of Bus stop & .082 & -.044 & -.005 & .065 & .801 & -.200 \\
\hline Accessibility & .222 & .407 & -.067 & -.045 & .579 & .183 \\
\hline $\begin{array}{l}\text { Cleanliness of Bus } \\
\text { stop }\end{array}$ & -.035 & -.351 & .265 & .143 & .563 & .477 \\
\hline Waiting Time & .370 & .014 & .034 & .234 & -.083 & .679 \\
\hline Travel Time & -.118 & .465 & -.136 & -.141 & -.033 & .498 \\
\hline
\end{tabular}

Source: Author

Cronbach's Alpha reliability test is conducted to measure the internal consistency i.e. reliability of the measuring instrument (Questionnaire). According to Table 5, Cronbach's Alpha value, 0.64 which is greater than 0.5 shows the results of the analysis are reliable.

Table 5: Reliability Statistics

\begin{tabular}{|c|c|c|}
\hline Cronbach's Alpha & $\begin{array}{c}\text { Cronbach's Alpha Based on } \\
\text { Standardised Items }\end{array}$ & N of Items \\
\hline .637 & .647 & 16 \\
\hline
\end{tabular}

Source: Author 


\section{CONCLUSIONS}

The study investigates factors of improving bus transferability as the choice mode of passengers at the Bambalapitiya railway station. The contribution of this study is the assessment of the passenger perspective on transfer mode choice and ascertain the service quality attributes for improving bus transferability. The study mainly considered sixteen quality attributes: accessibility, waiting time, cleanliness of the bus stop, facilities of the bus stop, occupancy level, safety of driving, traffic conflict, harassments, courtesy of bus crew, bus route coverage, bus frequency, availability, bus quality, privacy, cleanliness, and travel time that affect transfer mode choice.

The study focused on the perspectives of passengers who are currently not choosing bus transport as their transfer mode and the findings of the study reflect the factors of passenger mode choice which are useful to improve bus transferability at the Bambalapitiya Railway Station. The results of the descriptive analysis clearly show overcrowding and increased travel time are the most crucial factors for not choosing bus services as the transfer mode. The study provides a direction to transport policy decision-makers, regulators, and service providers to improve bus service quality and frequency while introducing new bus services during peak hours to minimise the overcrowding of buses and increase the efficiency of service.

The results of factor analysis show six groups of variables with similar characteristics. The six factors containing the sixteen quality attributes are network design, convenience, safety, quality of buses, background factors, and time consumption that could be used as variables for further analyses. According to the factor extraction, passengers are more concerned about network design. It represents bus route coverage avoiding further transfers, availability of service to their destination, and level of frequency which connects with the arrival time of trains. The study provides a guide to the government to nominate policy priorities for introducing new transfer bus services by both state and private sectors according to passenger demand for destination centres. Imposing and enforcing time schedules for bus dispatching is imperative to reduce waiting time for buses and travel time delays. The study gives a reasonable path ahead to the configuration of policies that will ensure more effective bus transferability to the existing bus users as well as attracting new passengers through an efficient rail-bus integration system.

\section{REFERENCES}

[1] M. Pitsiava-Latinopoulou, E. Zacharaki, S. Basbas, and I. Politis, "Passenger intermodal terminal stations: role and infrastructure", Urban Transport XIV, Vol 101: WIT Press, pp. 233- 242, 2008. 
[2] J. Castiglione, M. Bradley, and J. Gliebe, "Activity-Based Travel Demand Models, A Primer, Resource Systems Group, Inc. White River Junction, Vermont, 2015.

[3] National Transport Commission, National Transport Statistics- 2016. [ebook] Available at https://www.ntc.gov.lk/corporate/pdf/NTC\%20English\%20 Report\%20-\%202016.pdf [Accessed July 15 2015]

[4] A.S. Kumarage, T.L. Gunaruwan, D.S. Jayaweera, A.M.D. Bandusena, M,A, Jeffry, "National Policy on Transport In Sri Lanka, 2009

[5] Wikipedia, The Free Encyclopedia, Available: https://en.wikipedia.org /wiki/Transfer (public transit), [Accessed July 15 2015]

[6] G. Mintesnot and T. Shin-ei, “The Effect of Travelers' Level of Satisfaction on Transport Mode Choice: An Input for Policy Analysis", World Conference on Transport Research, California, 2007.

[7] Minal and C.R Sekhar, "Mode Choice Analysis: the Data, the Models and Future Ahead", International Journal for Traffic and Transport Engineering, 4(3), pp.269-285, 2014.

[8] X. Cheng, Y. Cao, K. Huang and Y. Wang, "Modeling the Satisfaction of Bus Traffic Transfer Service Quality at a High-Speed Railway Station”, Journal of Advanced Transportation, 2018.

[9] L.N. Jansen, M.B. Pedersen, O.A. Nielsen, "Minimising Passenger Transfer Times in Public Transport Timetables", 7th Conference of the Hong Kong Society for Transportation Studies, pp. 229-239, 2002.

[10] B.J. Berkley, "Designing services with function analysis", Journal of Hospitality \& Tourism Research 20(1): pp. 73-100, 1996.

[11] L. Leonard, A. Berry, and A. Parasuraman, "Five imperatives for improving service quality," Quality Control \& Applied Statistics, vol. 36, pp. 423-426, 1990.

[12] D. Dissanayake, S. Kurauchi, T. Morikawa and S. Ohashi, "Inter-regional and intertemporal analysis of travel behaviour for Asian metropolitan cities: case studies of Bangkok, Kuala Lumpur, Manila, and Nagoya”. Transport Policy 19 (1), pp.36-46, 2012.

[13] W.T. Lai, C.F. Chen, "Behavioral intentions of public transit passengers - the roles of service quality, perceived value, satisfaction and involvement". Transport Policy 18, pp. 318-325, 2011. 
[14] W.L. Chee and J.L. Fernandez, "Factors that influence the choice of mode of transport in Penang: a preliminary analysis". Procedia - Soc. Behav. Sci. 91 (225), pp. 120-127, 2013.

[15] M.D. Guillen, H. Ishida and N. Okamoto, "Is the use of informal public transport modes in developing countries habitual? An empirical study in Davao City, Philippines", Transport Policy 26, pp. 31-42, 2013.

[16] W. Jen and K.C. Hu, "Application of perceived value model to identify factors affecting passengers' repurchase intentions on city bus: A case of the Taipei metropolitan area," Transportation, vol. 30, no. 3, pp. 307-327, 2003.

[17] J. F. Petrick, "The roles of quality, value and satisfaction in predicting cruise passengers' behavioral intentions," Journal of Travel Research, vol. 42, no. 4, pp. 397-407, 2004.

[18] C.F. Chen, "Investigating structural relationships between service quality, perceived value, satisfaction, and behavioral intentions for air passengers: Evidence from Taiwan," Transportation Research Part A: Policy and Practice, vol. 42, no. 4, pp. 709-717, 2008.

[19] S. O. Olsen, "Repurchase loyalty: The role of involvement and satisfaction," Psychology \& Marketing, vol. 24, no. 4, pp. 315-341, 2007.

[20] N.G.M. Nor, A.R.M. Nor, and A.Z. Abdullah, "Predicting The Impact of Demand and Supply Side Measures on Bus Ridership in Putrajaya, Malaysia", Journal of Public Transportation, 9(5): pp. 57 - 71, 2006.

[21] J.M. Del Castillo and F.G. Benitez, "A methodology for modeling and identifying users satisfaction issues in public transport systems based on users surveys", Procedia - Soc. Behav.Sci. 54, pp.1104-1114, 2012.

[22] Y. Popuri, K. Proussaloglou, C. Ayvalik, F. Koppelman and A. Lee, "Importance of traveler attitudes in the choice of public transportation to work: findings from the Regional Transportation Authority Attitudinal Survey", Transportation (Amst). 38 (4), pp. 643-661, 2011.

[23] K. Shaaban and R. F. Khalil, "Proposed Policies to Support the New Metro System in Qatar," Procedia - Social and Behavioral Sciences, vol. 48, pp. 2315-2324, 2012.

[24] M. Abdel-Aty and P. Jovanis, "A Survey of the Elderly: An Assessment of Their Travel Characteristics", Proceedings of the 77th Annual Meeting of the Transportation Research Board, Washington, DC, USA, pp.11-15, 1998. 
[25] L. Redman, M. Friman, T. Gärling and T. Hartig, "Quality attributes of public transport that attract car users: A research review”. Transport Policy 25, pp.119-127, 2013.

[26] H. Yin, H. Guan, T. Liu and L Gong, "Study of urban resident travel mode choice behavior", Proceedings of the 10th International Conference of Chinese Transportation Professionals-Integrated Transportation Systems: Green, Intelligent, Reliable, ICCTP 2010, Beijing, China, pp. 4-8, 2010.

[27] A. Kostakis, "Measuring Customer Satisfaction in Public Transportation, An empirical study based in urban buses in the city of Larissa (Greece), The MUSA methodology": MIBES, pp. 260-275, 2009.

[28] R. Munzilah Md, D. C. Wijeyesekera and A.T.A. Karim, "Bus Operation, Quality Service and The Role of Bus Provider and Driver", Malaysian Technical Universities Conference on Engineering \& Technology, Procedia Engineering 53 (2013), pp.167 - 178, 2012.

[29] R.A.M. Madhuwanthi, A.Marasinghe, R.P.C. J. Rajapakse, A.D. Dharmawansa and S. Nomura, "Factors Influencing to Travel Behavior on Transport Mode Choice- A Case of Colombo Metropolitan Area in Sri Lanka", International Journal of Affective engineering, Vol 15 No. 2, pp 63-72, 2016.

[30] G. Mazzulla, and L. Eboli, “A Service Quality Experimental Measure for Public Transport, in European Transport”, Strasbourg. pp. 42 - 53, 2006.

[31] The Land Transport Authority. Public Transport Customer Satisfaction 2011. Available:

http://www.lta.gov.sg/content/dam/lta/media/COS12_PTCSS_Annex-A.pdf. [Accessed July 15 2015]

[32] B.D. Taylor and C.N.Y. Fink, "The Factors Influencing Transit Ridership: A Review and Analysis of the Ridership Literature", University of California, 2003.

[33] C. Chang-jun, Y.En-jian, L.Sha-sha, Z.Yong-sheng, and L.Jun, "Holiday Destination Choice Behavior Analysis Based on AFC Data of Urban Rail Transit", Research Article on Discrete Dynamics in Nature and Society, Hindawi Publishing Corporation, Article ID 136010, 2015. 